\title{
Can ecological land classification increase the utility of vegetation monitoring data?
}

Jeb C. Williamson ${ }^{\mathrm{a}}$, Brandon T. Bestelmeyer ${ }^{\mathrm{a}}$, Mitchel P. McClaran ${ }^{\mathrm{b}}$, Dan Robinett $\mathrm{c}^{\mathrm{c}}$, David D. Briske ${ }^{\mathrm{d}}, \mathrm{X}$. Ben $\mathrm{Wu}^{\mathrm{d}}$, and Maria Fernandez-Gimenez ${ }^{\mathrm{e}}$

aUSDA-ARS Jornada Experimental Range, New Mexico State University, Las Cruces, NM, USA

${ }^{\mathrm{b}}$ School of Natural Resources and the Environment, University of Arizona, Tucson, AZ, USA

${ }^{\mathrm{c}}$ Robinett Rangeland Resources LLC, Elgin, AZ, USA

${ }^{\mathrm{d}}$ Department of Ecosystem Science and Management, Texas A\&M University, College Station, TX, USA

${ }^{\mathrm{e}}$ Department of Forest and Rangeland Stewardship, Colorado State University, Fort Collins, CO, USA.

Corresponding author: Jeb C. Williamson, USDA-ARS Jornada Experimental Range, MSC 3JER, Box 30003, New Mexico State University, Las Cruces, NM 88003, USA. Email: jcwill@nmsu.edu 


\section{Abstract}

3 Vegetation dynamics in rangelands and other ecosystems are known to be mediated by

4 topoedaphic properties. Vegetation monitoring programs, however, often do not consider the

5 impact of soils and other sources of landscape heterogeneity on the temporal patterns observed.

6 Ecological sites (ES) comprise a land classification system based on soil, topographic, and

7 climate variations that can be readily applied by land managers to classify topoedaphic properties

8 at monitoring locations. We used a long-term ( $>40 \mathrm{y})$ vegetation record from southeastern

9 Arizona, USA to test the utility of an ES classification for refining interpretations of monitoring

10 data in an area of relatively subtle soil differences. We focused on two phenomena important to

11 rangeland management in the southeastern Arizona region: expansion of the native tree velvet

12 mesquite (Prosopis velutina Woot.) and spread of the introduced perennial grass Lehmann

13 lovegrass (Eragrostis lehmanniana Nees). Specifically, we sought to determine if a quantitative,

14 ES-specific analysis of the long-term record would 1) improve detection of changes in plant

15 species having heightened ecological or management importance and 2) further clarify

16 topoedaphic effects on vegetation trajectories. We found that ES class membership was a

17 significant factor explaining spatiotemporal variation in velvet mesquite canopy cover, Lehmann

18 lovegrass basal cover, and Lehmann lovegrass density measurements. In addition, we observed

19 that the potential magnitude of velvet mesquite and Lehmann lovegrass increases varied

20 substantially among ES classes. Our study brings attention to a practical land management tool

21 that might be called upon to increase the effectiveness of vegetation-based indicators of

22 ecosystem change. 


\section{Key words}

26 Biological invasion; Land classification; Monitoring; Soil texture; Time series; Vegetation

27 indicator

\section{Introduction}

Vegetation monitoring is one of the principal methods used to assess the ecological consequences of management actions and climate change at local to landscape scales (Herrick et al., 2005). Vegetation dynamics at these scales can vary strongly in response to topoedaphic heterogeneity (Bestelmeyer et al., 2011; Pringle et al., 2006; Wu and Archer, 2005). For example, even relatively subtle variations in soil profile properties, such as the depth to clay- or carbonate-rich horizons in otherwise similar soils, can cause variations in rates of shrub encroachment or grass mortality (Bestelmeyer et al., 2006; Browning et al., 2012). Vegetation monitoring programs, however, often do not consider the impact of topoedaphic heterogeneity on the temporal patterns observed, which can lead to misinterpretation of early warning indicators or the importance of anthropogenic or climatic variables being studied (Pringle et al., 2006).

To address the effects of topoedaphic properties, some authors have recommended that

42 monitoring sites be linked to soil- and climate-based land classification systems (Herrick et al.,

43 2006; Karl et al., 2010) such as the ecological site (ES) classifications used widely in the United

44 States (Brown, 2010; USDA-NRCS, 2013) and similar classifications used worldwide (Blanco et

45 al., 2014; Green and Klinka, 1994; Ray, 2001; van Gool and Moore, 1999). ES classes are

46 subdivisions of a landscape based on soil, topographic, and/or climate properties known to 
47 influence vegetation composition and change (Duniway et al., 2010). Each ES class is associated

48 with a state-and-transition model describing the vegetation changes that are likely to occur

49 following specific management actions or natural events (Bestelmeyer et al., 2009; López et al.

50 2013). Land areas belonging to the same ES class are expected to provide the same general

51 environment for plant establishment and growth. This expectation can give land managers

52 increased confidence that the knowledge they have acquired from a particular vegetation

53 monitoring effort can be effectively applied to other areas belonging to the same ES class (and

54 only cautiously applied to other areas). In addition, the criteria used to differentiate ES classes

55 are in most cases explicitly defined, which enables land managers to assess the degree of

56 similarity between two classes and determine the suitability of applying ecological knowledge

57 across class boundaries. In the US separate ES classifications are created on a per-region basis,

58 and individual ES classes are typically only utilized in that region they were developed for.

59 Given the important role of topoedaphic properties in controlling vegetation composition

60 and dynamics, best practices commonly call for the incorporation of topoedaphic strata into

61 vegetation monitoring designs. Use of ES classifications for landscape stratification is likely to

62 increase with official commitment by three prominent US land management agencies - the

63 Natural Resources Conservation Service, Forest Service, and Bureau of Land Management - to

64 utilize ES classifications as a basis for monitoring, assessment, and planning in rangelands

65 (BLM, 2010). ES classifications are already applied to a number of conservation activities and

66 therefore represent a sensible tool for linking monitoring programs to other aspects of land

67 management such as restoration projects and grazing plans. Nevertheless, there has been little

68 empirical study aimed at supporting or refuting the utility of ES classifications with regard to

69 ecosystem monitoring, despite recommendations to further incorporate ES classifications or 
similar frameworks into vegetation monitoring programs (Bestelmeyer et al., 2009; Herrick et al., 2006; Karl and Herrick, 2010).

We used an uncommonly long (>40 years), well-studied, and spatially extensive monitoring dataset available from the Santa Rita Experimental Range (SRER) to test for differences in vegetation trajectories among ES classes reflecting differences in subsoil properties in sandy soils of piedmont slope landforms. Long-term monitoring of ecological indicators is essential for resolving critical uncertainties in the detection of ecosystem trends, such as whether or not environmental degradation or improvement is taking place in ecosystems, like deserts, that respond slowly or episodically to management or climatic drivers. Increasing the effectiveness of ecological indicators may require addressing topoedaphic variation in a more systematic and detailed way than typically occurred in the past, and ES classification has been identified as one tool that could be used to address topoedaphic variation in such a manner (Bestelmeyer et al., 2009; Herrick et al., 2006). Our study provides a rare, empirical assessment of ES classification utility using an existing long-term monitoring dataset. By associating each SRER monitoring site with an ES class, we sought to determine if the detection of changes in plant species recognized as having heightened ecological or management importance in our study area would be improved. We also sought to determine whether previously unrecognized edaphic effects on vegetation trajectories had the potential to produce erroneous interpretations of vegetation monitoring data and associated indicators of ecosystem change. The ES classes studied here reflect differences in subsoil clay content that would likely go unnoticed by many observers without explicit consideration of ES classes, and earlier published analyses of the SRER long-term monitoring data did not address such soil variations. Finally, our study offered 
92 an opportunity to refine interpretations of a high-value long-term dataset and evaluate the need to

93 modify the current ES classification system.

\section{Methods}

97 2.1. Focal species

99 We limited our analysis to two plant species having great management significance in the 100 southeastern Arizona region: velvet mesquite (Prosopis velutina Woot.) and Lehmann lovegrass 101 (Eragrostis lehmanniana Nees). Velvet mesquite is a small tree native to portions of Arizona, 102 California, and New Mexico. Historically abundant on the SRER primarily along ephemeral 103 drainages, the species has since colonized most upland areas of the research property (McClaran, 104 2003; McClaran et al., 2010). Expansion of velvet mesquite on the SRER is an example of a 105 more widespread pattern of woody plant encroachment and thickening that has occurred across 106 much of the western United States over the past century (Van Auken, 2000; Van Auken, 2009).

107 Management of woody vegetation continues to be emphasized in many areas, and herbaceous-towoody type conversions are featured prominently in state-and-transitions models currently

109 described for US rangelands (Twidwell et al., 2013).

111 parts of the southwestern United States to increase livestock forage on degraded rangelands (Cox 112 et al., 1988). Despite its benefits as forage, the species has proven to be an undesirable invader of 113 areas managed to promote native vegetation and associated ecosystem services. The species is 114 known to replace native grasses given suitable climatic and edaphic conditions (Angell and 115 McClaran, 2001; Bock et al., 2007). Like expansion of the native velvet mesquite, the spread of 
116 Lehmann lovegrass exemplifies an ecological syndrome affecting large areas of the western

117 United States - the replacement of native plants by invasive nonnative grasses. In some of the

118 more extreme examples of this phenomenon, nonnative grass introduction has resulted in regime

119 shifts from shrub and/or cactus dominated ecosystems to ecosystems dominated by grasses, often

120 with important impacts on plant biodiversity and wildlife habitat (Knapp, 1996; Marlette and

121 Anderson, 1986; Olsson et al., 2012; Whisenant, 1990).

122

123 2.2. Monitoring dataset

124

125 Permanent vegetation monitoring plots were established on the SRER by several independent

126 and temporally disjointed studies. Monitoring locations were generally not selected in a strictly

127 random or stratified-random fashion. Consistent collection methods enabled data from these

128 plots to be later compiled into a single long-term monitoring dataset, available online from the

129 University of Arizona (http://cals.arizona.edu/srer/data.html see On-going Long-Term

130 Measurements; McClaran et al., 2002). Standard measurements performed at each monitoring

131 plot included the total amount of velvet mesquite canopy cover and Lehmann lovegrass basal

132 cover intersecting a single 30.4 m transect. Beginning in 1972, perennial grass density was

133 estimated using plant counts within a $0.3 \times 30.4 \mathrm{~m}$ belt transect running parallel to, and having

134 one side bounded by, the line-intercept transect. The number of plots revisited on the SRER

135 increased through time as new studies were initiated. Our analysis was limited to velvet mesquite 136 canopy cover measurements collected from 1975 through 2012, Lehmann lovegrass basal cover

137 measurements collected from 1984 through 2012, and Lehmann lovegrass density measurements

138 collected from 1972 through 2012 (at the same 48 plots in each case). These time periods were 
139 selected based on our desire to maximize sample sizes while ensuring that the same number of 140 samples were collected at each sample date. We also limited our analysis to those plots not

141 altered by wildfire or intentionally cleared of velvet mesquite during the 41 year analysis period

142 (McClaran and Angell, 2006) to interpret edaphic effects on velvet mesquite and Lehmann 143 lovegrass dynamics more easily.

144

145

146

147

148

149

150

151

152

153

154

155

156

157

158

159

160

161

\subsection{Ecological site classes}

Each monitoring plot was assigned a single ES class based on characterization of soil pits by an experienced observer (D. Robinett). Soil pits were excavated at a representative point along each monitoring transect, or in the dominant soil type intersected by the transect when more than one soil type was detected. As is the case in many areas, soil maps alone were not sufficient to assign plots to the correct ES class because the mapping resolution is typically 150-200 ha and multiple ES classes can occur within individual map units. Monitoring plots were predominantly associated with loamy upland (LU), sandy loam deep (SLD), and sandy loam upland (SLU) ecological site classes in the 300-400 mm precipitation zone (Land Resource Unit C) of Major Land Resource Area 41. We focused our analyses on these three classes and did not consider plots belonging to the other, less well represented ES classes found on the SRER. As a result, the labels LU, SLD, and SLU refer specifically to ecological sites R041XC313AZ, R041XC318AZ, and R041XC319AZ described in the Ecological Site Information System maintained by the Natural Resources Conservation Service (USDA-NRCS, 2013). In our study area the LU, SLD, and SLU sites occur most commonly on alluvial fans, are intermingled at a landscape level, and represent subtle differences in soil profile development. All three ES classes are typically 
162 characterized by loamy sand or sandy loam surface textures (Table 1). Soils of the SLD class, 163 however, are coarse textured to at least $100 \mathrm{~cm}$ below the surface, whereas LU and SLU soils 164 exhibit a notable clay increase with depth. The primary difference between LU and SLU 165 ecological sites is the depth of this argillic (relatively clay rich) horizon. State-and-transition 166 models associated with the LU, SLD, and SLU classes indicate the potential for velvet mesquite 167 to invade and increase to as much as $25 \%$ canopy cover on all three sites. The same models also 168 describe the potential for the herbaceous understory of all three sites to transition from a native 169 perennial and/or annual grass dominated community to a community dominated by Lehmann 170 lovegrass. 


\section{Table 1}

172 Soil characteristics distinguishing the three ecological site classes most commonly associated

173 with Santa Rita Experimental Range long-term monitoring plots.

\begin{tabular}{ll}
\hline Ecological site class & Distinguishing soil characteristics \\
\hline Loamy upland (LU) & (1) Sandy loam to loam surface textures 2.5-10 cm deep (2.5-20 cm for gravelly sandy loam). \\
& (2) Argillic (relatively clay rich) horizons near the surface. \\
\hline Sandy loam deep (SLD) & (1) Loamy sand to sandy loam surface textures. \\
\hline Sandy loam upland (SLU) & (1) Sandy loam surface textures at least $10 \mathrm{~cm}$ deep (20 cm for gravelly sandy loam). \\
& (2) Argillic (relatively clay rich) horizons at shallow depths. \\
\hline
\end{tabular}

174 
177 Two complementary approaches were used to test for differences in velvet mesquite and

178 Lehmann lovegrass dynamics among ES classes. Our first approach was to characterize time

179 series data by computing mean and maximum values of velvet mesquite canopy cover, Lehmann

180 lovegrass basal cover, and Lehmann lovegrass density recorded at individual plots. The Kruskal-

181 Wallis test was used to identify significant differences in mean and maximum values among and

182 between ES classes.

183 Our second approach was to distill information from velvet mesquite and Lehmann

184 lovegrass time series using multivariate statistical techniques. Multivariate statistics are

185 commonly employed in plant ecology to assess vegetation differences among study sites based

186 on the presence or abundance (e.g., cover or density) of multiple plant species. We used an

187 analogous approach to compare monitoring plots based on the temporal profile of repeated velvet 188 mesquite or Lehmann lovegrass measurements (Potgieter et al., 2007). Multivariate statistics 189 were selected over linear or nonlinear mixed models because of the high degree of variation 190 among sample plots (both within and between ES classes) in initial density/cover values and 191 subsequent trajectories. Separate analyses were performed using repeated measures of velvet 192 mesquite canopy cover, Lehmann lovegrass basal cover, or Lehmann lovegrass density as 193 multiple (potentially correlated) attributes of individual monitoring plots. For all analyses, 194 dissimilarity of plot pairs was computed as the Euclidean distance between plots in multivariate 195 space. Plots exhibiting similar cover or density trends over time were expected to be separated by 196 smaller overall distances. Permutation-based analysis of variance (PERMANOVA; Anderson, 197 2001) was applied to dissimilarity matrices in order to evaluate the importance of ES class 
membership as a source of variation (50 000 permutations using the adonis function in the $\mathrm{R}$ package vegan; Oksanen et al., 2013). To test if plots within a particular ES class were more dispersed in multivariate space than those belonging to another class, we calculated the distance between each plot and the spatial median of its associated ES class (betadisper function in the $\mathrm{R}$ package vegan; Anderson, 2006). Permutation-based analysis of variance was then performed on the resulting distances (10 000 permutations). An alpha level of 0.05 was used for all significance tests, and no effort was made to test for or address non-normal data distributions.

Vegetation trajectories of multiple sample plots can be difficult to visualize and compare using line graphs or other simple graphing techniques. Multivariate cluster analysis enabled us to better visualize differences in velvet mesquite and Lehmann lovegrass dynamics among study plots and ES classes (Fig. 1). Plots were grouped into a predefined number of clusters using the Euclidean dissimilarity matrix described above (pam function in the R package cluster; Maechler et al., 2013; Reynolds et al., 1992). We then computed 25\%, 50\%, and 75\% quantiles of cover or density measurements for each cluster at each sample date. Numerous statistical methods are available to assess the appropriateness of different cluster solutions, and we explored several of these options to help determine a reasonable number of clusters for our analysis. Plotting three separate measures - within-cluster sum of squares (kmeans function in the R package stats), mean dissimilarity between cluster members and cluster medoids (pam function in the R package cluster), and the gap statistic for goodness of clustering (clusGap function in the R package cluster) - as a function of cluster count generally led to similar interpretations about reasonable cluster numbers (see Appendix A). Prospective cluster numbers were also judged according to their perceived utility for visualizing trends (e.g., a large number of clusters might do little to simplify visualizations). 
Compared to SLU plots $(n=18)$, plots assigned to the SLD $(n=24)$ class exhibited a broader

227 distribution of mean and maximum velvet mesquite canopy cover values (Fig. 2). Median values

228 of these two summary statistics were also higher for the SLD class than for the SLU class.

229 Kruskal-Wallis tests indicated a significant difference in mean velvet mesquite canopy cover

230 between SLD and SLU plots and a nearly significant difference $(P=0.0534)$ in maximum

231 canopy cover values between these two ES classes (Table 2). In contrast, LU plots $(n=6)$ could

232 not be distinguished from SLD or SLU plots based on mean and maximum velvet mesquite

233 canopy cover.

Mean and maximum Lehmann lovegrass basal cover and density values were also

237 lovegrass, median values of both summary statistics were higher for the SLU class than for the

238 SLD class (Fig. 2). Median values tended to be even higher within the LU class. Kruskal-Wallis

239 tests indicated significant differences in all Lehmann lovegrass summary statistics between LU

240 and SLD plots. Mean basal cover and density differed significantly between LU and SLU plots,

241 while maximum basal cover and density did not. Statistical comparisons involving the LU class,

242 however, may not be highly reliable given the small number of LU plots sampled. 


\section{Table 2}

245 Between-ecological site comparisons of select time series summary statistics (mean and

246 maximum) using the Kruskal-Wallis test.

247

\begin{tabular}{lrrrrrrr}
\hline & \multicolumn{5}{c}{ Kruskal-Wallis P-value } \\
\cline { 2 - 8 } & \begin{tabular}{c} 
Velvet mesquite \\
canopy cover \\
Ecological \\
\cline { 2 - 8 } site classes
\end{tabular} & $\begin{array}{c}\text { Lehmann } \\
\text { lovegrass } \\
\text { basal cover } \\
(1984-2012)\end{array}$ & $\begin{array}{c}\text { Lehmann } \\
\text { lovegrass } \\
\text { density } \\
(1972-2012)\end{array}$ \\
\hline All & 0.0723 & 0.1010 & $<0.0001$ & 0.0019 & $<0.0001$ & 0.0053 \\
LU, SLD & 0.4521 & 0.8968 & 0.0006 & 0.0051 & 0.0002 & 0.0082 \\
LU, SLU & 0.1171 & 0.1023 & 0.0092 & 0.7138 & 0.0007 & 0.2712 \\
SLD, SLU & 0.0360 & 0.0534 & 0.0018 & 0.0033 & 0.0048 & 0.0127 \\
\hline
\end{tabular}

LU, loamy upland; SLD, sandy loam deep; SLU, sandy loam upland 
Results of multivariate analyses were similar to those described above for time series summary

252 statistics. ES class membership was found to be a significant predictor of variation in velvet

253 mesquite canopy cover, Lehmann lovegrass basal cover, and Lehmann lovegrass density among

254 monitoring plots through time (see Adonis in Table 3). The amount of variance explained by ES

255 class was, however, rather modest in all cases. Permutation-based analysis of variance indicated

256 partial $R^{2}$ values of $0.13,0.25$, and 0.22 for velvet mesquite canopy cover, Lehmann lovegrass

257 basal cover, and Lehmann lovegrass density, respectively, when applied to data representing all

258 three ES classes.

259 We also observed significant differences in the dispersion of plots belonging to different

260 ES classes when either velvet mesquite canopy cover or Lehmann lovegrass basal cover was the

261 focus of our analysis (see BD in Table 3). For velvet mesquite canopy cover, SLD plots were

262 dispersed relatively widely in multivariate space compared to LU and SLU plots. Average

263 distance of SLD plots to the ES class spatial median was $44.1 \%$ cover, compared to $28.1 \%$ for

264 LU plots and 22.1\% for SLU plots. For Lehmann lovegrass basal cover, average distance of plots

265 to the respective ES class spatial median was 4.3\% cover for LU plots, $2.9 \%$ for SLD plots, and

$2664.8 \%$ for SLU plots. The null hypothesis of homogenous dispersion could not be rejected in the

267 case of Lehmann lovegrass density.

268 Plots were grouped into four clusters to better visualize variation in velvet mesquite

269 canopy cover trends through time (Fig. 3A). These clusters differed most notably with regard to

270 1) canopy cover at the start of the time series and 2) the amount of canopy cover change (both

271 increases and decreases) over the study period. Plots with relatively low initial canopy cover 
272 tended to exhibit relatively little absolute change in canopy cover (e.g., group 1). The opposite

273 was true for plots with relatively high initial canopy cover (e.g., groups 3 and 4). The four

274 clusters derived using velvet mesquite canopy cover were not evenly represented in the three ES

275 classes studied (Fig. 3B). The two groups characterized by relatively low velvet mesquite cover

276 (groups 1 and 2) were reasonably well represented in all three ES classes. In contrast, the two

277 groups characterized by relatively high cover (groups 3 and 4) did not occur in the SLU class. In

278 addition, the group with the greatest cover (group 4) was only represented in the SLD class.

279 Four plot clusters (different from those described above) were derived to visualize

280 variation in Lehmann lovegrass basal cover trends (Fig. 4A), and an additional four clusters were

281 derived to visualize variation in Lehmann lovegrass density trends (Fig. 5A). Both vegetation

282 properties tended to follow hump shaped curves that peaked between the years 1990 and 2000.

283 Plot clusters based on these vegetation properties differed most notably with regard to the

284 maximum height of the basal cover or density curve. In the case of Lehmann lovegrass density,

285 another notable difference was the number of plants recorded early in the time series. For basal

286 cover, all four groups (i.e., clusters) were represented in the SLU class, but the group with the

287 greatest Lehmann lovegrass cover (group 4) was not represented in the SLD class, and the group

288 with the lowest cover (group 1) was not present in the LU class (Fig. 4B). In a similar fashion, all

289 four groups derived using Lehmann lovegrass plant density were represented in the SLU class

290 (Fig. 5B). The group exhibiting the least amount of change over time (group 1) was absent from

291 the LU class, but this group made up a larger proportion of the SLD class than did any other

292 group. The group most commonly represented in the SLU class was the group having a relatively

293 high density peak on or around the 1991 sample date (group 3). 


\section{Table 3}

296 Between-ecological site comparison of velvet mesquite canopy cover, Lehmann lovegrass basal

297 cover, and Lehmann lovegrass density using PERMANOVA multivariate analyses of variance

298 (adonis function in the $\mathrm{R}$ package vegan) and dispersion (BD, betadisper function in the $\mathrm{R}$

299 package vegan). Repeated measures of cover or density were treated as multiple attributes of

300 individual monitoring plots, and pairwise dissimilarity of plots was calculated as the Euclidean

301 distance between plots in multidimensional space.

302

\begin{tabular}{|c|c|c|c|c|c|c|c|c|c|}
\hline \multirow[b]{2}{*}{$\begin{array}{l}\text { Ecological } \\
\text { site classes } \\
\end{array}$} & \multicolumn{3}{|c|}{$\begin{array}{l}\text { Velvet mesquite } \\
\text { canopy cover } \\
(1975-2012)\end{array}$} & \multicolumn{3}{|c|}{$\begin{array}{c}\text { Lehmann lovegrass } \\
\text { basal cover } \\
(1984-2012)\end{array}$} & \multicolumn{3}{|c|}{$\begin{array}{c}\text { Lehmann lovegrass } \\
\text { density } \\
(1972-2012) \\
\end{array}$} \\
\hline & $\begin{array}{r}\text { Adonis } \\
R^{2}\end{array}$ & $\begin{array}{l}\text { Adonis } \\
P \text {-value }\end{array}$ & $\begin{array}{r}\text { BD } \\
P \text {-value }\end{array}$ & $\begin{array}{r}\text { Adonis } \\
R^{2}\end{array}$ & $\begin{array}{l}\text { Adonis } \\
P \text {-value }\end{array}$ & $\begin{array}{r}\text { BD } \\
P \text {-value }\end{array}$ & $\begin{array}{r}\text { Adonis } \\
R^{2}\end{array}$ & $\begin{array}{l}\text { Adonis } \\
P \text {-value }\end{array}$ & $\begin{array}{r}\text { BD } \\
P \text {-value }\end{array}$ \\
\hline All & 0.132 & 0.0251 & 0.0013 & 0.250 & 0.0003 & 0.0349 & 0.219 & $<0.0001$ & 0.0843 \\
\hline LU, SLD & 0.023 & 0.4442 & 0.1090 & 0.334 & 0.0002 & 0.1861 & 0.288 & $<0.0001$ & 0.0523 \\
\hline LU, SLU & 0.137 & 0.0363 & 0.3277 & 0.082 & 0.1395 & 0.7086 & 0.186 & 0.0034 & 0.2257 \\
\hline SLD, SLU & 0.130 & 0.0105 & 0.0002 & 0.174 & 0.0014 & 0.0094 & 0.078 & 0.0266 & 0.1688 \\
\hline
\end{tabular}

BD, betadisper function; LU, loamy upland; SLD, sandy loam deep; SLU, sandy loam upland 


\section{Discussion}

307 This study utilized a long-term vegetation record from southeastern Arizona to address a simple

308 question: Can a readily-accessed ecological land classification, representing subtle topoedaphic

309 variations that might otherwise go unnoticed by researchers, improve interpretations of

310 vegetation monitoring data? We found that incorporating an ES classification into our analysis of

311 a long-term monitoring dataset helped to explain spatial variations in the magnitude of historical

312 vegetation change, even though overall trends of velvet mesquite and Lehmann lovegrass

313 increase in our study area could be readily interpreted without consideration of ES classes. This

314 result provides a unique example of the potential value of ES classifications and, more broadly,

315 the association of monitoring data with topoedaphic information.

\section{4.1. Overall detection of vegetation change}

319 Early detection of undesirable vegetation change is one potentially important application of 320 vegetation monitoring and associated ecological indicators. Yet, there are instances where a 321 particular change may be less likely to occur or less pronounced in some portions of a landscape 322 compared to others due to geographic variation in topoedaphic properties (Bestelmeyer et al., 323 2006; Eggemeyer and Schwinning, 2009; Molinar et al., 2002; Wu and Archer, 2005). Although 324 monitoring programs that do not account for such topoedaphic variation may be unable to detect 325 important vegetation changes, we found that soil heterogeneity on the SRER was not sufficient 326 to prevent detection of velvet mesquite and Lehmann lovegrass increases during the study

327 period. Our analysis showed that velvet mesquite increases and Lehmann lovegrass invasion 
occurred to some extent within all three ES classes studied (Figs. 3, 4, and 5). In addition, the ES classes studied here did not exhibit strongly contrasting patterns of velvet mesquite and Lehmann lovegrass dynamics that could have obscured changes in central tendencies over the study area as a whole. These broad similarities reflect the relatively subtle edaphic differences between LU, SLD, and SLU sites and the fact that the sites occur within the same climatic zone.

\subsection{Topoedaphic effects on velvet mesquite and Lehmann lovegrass dynamics}

Landscape-level characterizations of vegetation change often obscure important spatiotemporal variation at finer scales. Moreover, rates and patterns of vegetation change often have as much management relevance as do shifts in the mere presence or absence of certain plant species. While changes in velvet mesquite and Lehmann lovegrass cover and density were readily observed in the SRER monitoring data irrespective of ES membership, the specific pattern of those changes differed among ES classes (Tables 2 and 3). Two approaches employed here, multivariate analyses and analyses of time series summary statistics, both showed ES class membership to be a significant factor explaining spatiotemporal variation in velvet mesquite canopy cover, Lehmann lovegrass basal cover, and Lehmann lovegrass density measurements collected over the past $\sim 40$ years.

Statistical clustering of monitoring plots based on their temporal trajectories helped to further clarify how vegetation dynamics differed among ES classes. Cluster analyses suggested that measurements associated with a single ES class tended to misrepresent the potential magnitude of velvet mesquite and Lehmann lovegrass increases within the other ES classes. For example, plots having relatively low velvet mesquite canopy cover through time (groups 1 and 2; 
351 Fig. 3) occurred in both the SLD and SLU classes, but the two clusters exhibiting the highest

352 velvet mesquite canopy cover (groups 3 and 4) were not represented in the SLU class. Similarly,

353 plots with the smallest increases in Lehmann lovegrass basal cover (groups 1 and 2; Fig. 4) were

354 represented in both the SLD and SLU classes, but plots with the greatest increase of Lehmann

355 lovegrass cover (group 4) occurred only in the SLU class.

356 These results have four notable, globally-relevant implications for the interpretation of

357 monitoring data and associated ecological indicators. First, because patterns of vegetation change

358 were found to differ among the ES classes studied on the SRER, our results reinforce the

359 potential importance of considering even subtle topoedaphic variation when assessing the

360 magnitude of vegetation change and applying vegetation-based indicators. The development of

361 ecological land class-specific guidelines for interpreting certain ecological indicators could help

362 to reduce misinterpretations arising from topoedaphic effects. Our results also corroborate the

363 value of subdividing the generally sandy soils in the study region into the three ES classes

364 evaluated.

Second, our study illustrates the potential limitations of applying interpretations beyond

366 the specific land types or physical settings being monitored (e.g., Bestelmeyer et al., 2011;

367 Pringle et al., 2006). One of the key premises of ecological land classification-based

368 management frameworks is that future management actions are likely to have more predictable

369 outcomes if information specific to the ecological land classes being managed is available from

370 previous monitoring activities. Our findings support this assertion, indicating that certain

371 information would be lost if observations from a single ES class were used to characterize the

372 dynamics of the other two classes. Additional study is needed to determine if, and how, such 
373 information could be used to improve ecosystem restoration strategies or more effectively

374 combat new velvet mesquite or Lehmann lovegrass invasions (e.g., Wonkka et al. 2016).

375 Third, sufficient sample size is needed in a monitoring effort to represent the central

376 tendency (i.e., mean or median) as well as the variation of vegetation values associated with

377 specific ES classes. Consider, for example, a scenario in which insufficient sample size resulted

378 in the high velvet mesquite cluster (group 4; Fig. 3) being under-represented in the SLD class or

379 the high Lehmann lovegrass cluster (group 4; Fig. 4) being under-represented in the SLU class.

380 In either case, such under-representation would have limited the ability to distinguish the SLU

381 and SLD classes.

382

Fourth, the length of time represented in the monitoring record will determine the ability

383 to detect differences among ES classes. For example, differences in Lehmann lovegrass cover

384 among ES classes were most apparent prior to 1996, but nearly indistinguishable since. Strong

385 meteorological events are associated with these patterns: the sharp increase of Lehmann

386 lovegrass is associated with very wet conditions in the 1980s, and Lehmann lovegrass decline is

387 associated with prolonged dry and warm conditions since 1996 (McClaran and Wei, 2014). Thus,

388 a longer record improves the ability to identify differences in the potential responses of

389 vegetation among the ES classes.

390 Our conclusions regarding topoedaphic effects on velvet mesquite and Lehmann

391 lovegrass dynamics are tempered by the recognition that SRER monitoring plots were not

392 established according to a random sampling design, as one would desire if the objective is to

393 extend inference to other parts of the SRER and southeastern Arizona region. Sampling bias

394 alone could conceivably explain the significant difference in velvet mesquite canopy cover

395 reported here between SLD and SLU plots. Our analysis indicated a strong correlation between 
velvet mesquite measurements taken at different times in the study period, which means that

397 choices made at the outset of a monitoring experiment could have considerable influence on observations later on. Nevertheless, we have little reason to suspect that SRER monitoring

399 locations were selected in a way that favored SLD sites with relatively high velvet mesquite cover, and our findings generally agree with other studies of edaphic effects on velvet mesquite establishment and growth. For example, the spatial distribution of honey mesquite (Prosopis glandulosa Torr.) groves and herbaceous openings on the La Copita Research Area in southern

403 Texas was found to align closely with the absence or presence, respectively, of a well-developed 404 argillic soil horizon (Archer, 1995). Similarly, Browning et al. (2008) studied historical mesquite 405 406 expansion on the SRER using aerial photography and soil mapping data and found that velvet mesquite proliferated more rapidly in sandy map units compared to clayey map units, even though canopy cover on the two soil types eventually converged on similar values over time. The tendency for velvet mesquite canopy cover to be higher at SLD plots than at SLU plots is also consistent with expectations based on the contrasting hydrological properties of fine 410 and coarse textured soils. Velvet mesquite plants growing on SLD sites are likely to have greater 411 overall access to soil moisture due to the infiltration-promoting characteristics of sandy soils and 412 the relatively extensive root system of this tree species (Fravolini et al., 2005; Noy-Meir, 1973).

413 On the other hand, enhanced surface drying of coarse textured soils may make SLD sites less 414 suitable than SLU sites to relatively shallow rooted herbaceous species such as Lehmann 415 lovegrass. This phenomenon, together with the potential for argillic horizons to reduce moisture 416 loss from the Lehmann lovegrass rhizosphere, may provide a mechanistic explanation as to why 417 SLU plots tended to exhibit greater mean and maximum Lehmann lovegrass basal cover and 418 density over time compared to SLD plots (English et al., 2005). McClaran et al. (2010) suggested 
419 a link between deep sandy soils and poor representation of Lehmann lovegrass based on repeated 420 ground photographs taken on the SRER. Edaphic controls on tree:grass ratios have also been

421 identified in African and Australian savannas (Sankaran et al., 2005; Walker and Langridge,

422 1997). Interestingly, mean and maximum Lehmann lovegrass basal cover and density values

423 recorded at LU monitoring plots tended to be even higher than those recorded at SLU plots, a

424 difference we cannot readily explain using the general models of plant-soil-moisture interactions 425 noted above.

426

427 5. Summary

428

429 ES classifications have been adopted by land management agencies in the US and other countries 430 as frameworks for developing land unit-specific management recommendations, models of 431 vegetation dynamics (e.g., state-and-transition models), and protocols for assessing ecosystem 432 health. Monitoring activities, in turn, are recognized as an important tool for collecting 433 information that can be used to support the development, testing, and refinement of vegetation 434 change models, management approaches, and ecosystem health indicators. Monitoring datasets 435 that span relatively long time periods afford unique opportunities to evaluate the utility of 436 existing ES classification schemes. In our analysis of the SRER long-term vegetation record, we 437 found that two vegetation changes important to land management in the southeastern Arizona 438 region differed significantly between closely-related ES classes common to the study area. While 439 these differences might not be large enough to warrant a reformulation of current land 440 management prescriptions - and overall trends of velvet mesquite and Lehmann lovegrass 441 increase on the SRER could be readily interpreted without consideration of ES classes - they 
442 nonetheless illustrate how information about even subtle soil differences can be used to

443 understand spatiotemporal variations in the magnitude of change that were previously

444 unexplained. Post-hoc assignment of monitoring points to ES (or similar) classes and, more

445 effectively, the use of ES classes as strata in the design of new monitoring programs could help

446 to reduce misinterpretation of monitoring data and contribute to a more comprehensive

447 understanding of landscape dynamics.

448

449 Acknowledgements

450

451 This research was supported in part by USDA CSREES grants 2007-38415-18637 and 2008-

$452 \quad 51130-19567$.

453

454 References

455

456 Anderson, M.J., 2001. A new method for non-parametric multivariate analysis of variance.

457 Austral Ecology. 26, 32-46.

458

459 Anderson, M.J., 2006. Distance-based tests for homogeneity of multivariate dispersions.

460 Biometrics. 62, 245-253.

461

462 Angell, D.L., McClaran, M.P., 2001. Long-term influences of livestock management and a non-

463 native grass dynamics in the Desert Grassland. Journal of Arid Environments. 49, 507-520. 
465 Archer, S., 1995. Tree-grass dynamics in a Prosopis-thornscrub savanna parkland: reconstructing

466 the past and predicting the future. Ecoscience. 2, 83-99.

467

468 Bestelmeyer, B.T., Goolsby, D.P., Archer, S.R., 2011. Spatial perspectives in state-and-transition 469 models: a missing link to land management? Journal of Applied Ecology. 48, 746-757.

471 Bestelmeyer, B.T., Tugel, A., Peacock, G.L., Robinett, D., Shaver, P.L., Brown, J., Herrick, J.E.,

472 Sanchez, H., Havstad, K.M., 2009. State-and-transition models for heterogeneous landscapes: a 473 strategy for development and application. Rangeland Ecology and Management. 62, 1-15.

474

475 Bestelmeyer, B.T., Ward, J.P., Havstad, K.M., 2006. Soil-geomorphic heterogeneity governs 476 patchy vegetation dynamics at an arid ecotone. Ecology. 87, 963-973.

477

478 Blanco, P.D., del Valle, H.F., Bouza, P.J., Metternicht, G.I., Hardtke, L.A., 2014. Ecological site 479 classification of semiarid rangelands: Synergistic use of Landsat and Hyperion imagery.

480 International Journal of Applied Earth Observation and Geoinformation. 29, 11-21.

481

482 Bock, C.E., Bock, J.H., Kennedy, L., Jones, Z.F., 2007. Spread of non-native grasses into grazed 483 versus ungrazed desert grasslands. Journal of Arid Environments. 71, 229-235.

484

485 Brown, J.R., 2010. Ecological sites: their history, status, and future. Rangelands. 32, 5-8. 
487 Browning, D.M., Archer, S.R., Asner, G.P., McClaran, M.P., Wessman, C.A., 2008. Woody

488 plants in grasslands: post-encroachment stand dynamics. Ecological Applications. 18, 928-944.

489

490 Browning, D.M., Duniway, M.C., Laliberte, A.S., Rango, A., 2012. Hierarchical analysis of 491 vegetation dynamics over 71 years: soil—rainfall interactions in a Chihuahuan Desert ecosystem.

492 Ecological Applications. 22, 909-926.

493

494 [BLM] Bureau of Land Management, 2010. Rangeland Interagency Ecological Site Manual. US

495 Department of the Interior, Bureau of Land Management, Manual 1734-1, Washington, D.C.

496 http://directives.sc.egov.usda.gov/OpenNonWebContent.aspx?content=27123.wba.

497

498 Cox, J.R., Martin-R, M.H., Ibarra-F, F.A., Fourie, J.H., Rethman, N.F.G., Wilcox, D.G., 1988.

499 The influence of climate and soils on the distribution of four African grasses. Journal of Range

500 Management. 41, 127-139.

501

502 Duniway, M.C., Bestelmeyer, B.T., Tugel, A., 2010. Soil processes and properties that

503 distinguish ecological sites and states. Rangelands. 32, 9-15.

504

505 Eggemeyer, K.D., Schwinning, S., 2009. Biogeography of woody encroachment: why is 506 mesquite excluded from shallow soils? Ecohydrology. 2, 81-87. 
508 English, N.B., Weltzin, J.F., Favolini, A., Thomas, L., Williams, D.G., 2005. The influence of 509 soil texture and vegetation on soil moisture under rainout shelters in a semi-desert grassland.

510 Journal of Arid Environments. 63, 324-343.

511

512 Fravolini, A., Hultine, K.R., Brugnoli, E., Gazal, R., English, N.B., Williams, D.G., 2005.

513 Precipitation pulse use by an invasive woody legume: the role of soil texture and pulse size.

514 Oecologia. 144, 618-627.

515

516 Green, R.N., Klinka, K., 1994. A field guide for site identification and interpretation for the

517 Vancouver Forest Region. British Columbia Ministry of Forests, Victoria, B.C. Land

518 Management Handbook. 28p.

519

520 Herrick, J.E., Bestelmeyer, B.T., Archer, S., Tugel, A.J., Brown, J.R., 2006. An integrated

521 framework for science based arid land management. Journal of Arid Environments. 65, 319-335.

522

523 Herrick, J.E., Van Zee, J.W., Havstad, K.M., Burkett, L.M., Whitford, W.G., 2005. Monitoring

524 Manual for Grassland, Shrubland and Savanna Ecosystems. Volume II: Design, Supplementary

525 Methods and Interpretation. USDA-ARS Jornada Experimental Range, Las Cruces, New

526 Mexico.

527

528 Karl, J.W., Herrick, J.E., 2010. Monitoring and assessment based on ecological sites.

529 Rangelands. 32, 60-64.

530 
531 Knapp, P.A., 1996. Cheatgrass (Bromus tectorum L.) dominance in the Great Basin Desert.

532 Global Environmental Change. 6, 37-52.

534 López, D.R., Brizuela, M.A., Willems, P., Aguiar, M.R., Siffredi, G., Bran, D., 2013. Linking

535 ecosystem resistance, resilience, and stability in steppes of North Patagonia. Ecological

536 Indicators. 24, 1-11.

537

538 Maechler, M., Rousseeuw, P., Struyf, A., Hubert, M., Hornik, K., 2013. Cluster: cluster analysis 539 basics and extensions. R package version 1.14.4.

540

541 Marlette, G.M., Anderson, J.E., 1986. Seed banks and propagule dispersal in crested-wheatgrass 542 stands. Journal of Applied Ecology. 23, 161-175.

543

544 McClaran, M.P., 2003. A century of vegetation change on the Santa Rita Experimental Range, 545 in: McClaran, M.P., Ffolliott, P.F., Edminster, C.B. (Tech. Coords.), Proceedings: Santa Rita 546 Experimental Range: 100 years (1903 to 2003) of Accomplishments and Contributions. US

547 Department of Agriculture, Forest Service, RMRS-P-30, Ogden, UT, pp. 16-33.

548

549 McClaran, M.P., Angell, D.L., 2006. Long-term vegetation response to mesquite removal in 550 Desert Grassland. Journal of Arid Environments. 66, 686-697. 
552 McClaran, M.P., Angell, D.L., Wissler, C., 2002. Santa Rita Experimental Range Digital

553 Database: User’s Guide. US Department of Agriculture, Forest Service, RMRS-GTR-100,

554 Ogden, Utah.

555

556 McClaran, M.P., Browning, D.M., Huang, C., 2010. Temporal dynamics and spatial variability

557 in desert grassland vegetation, in: Webb, R.H., Boyer, D.E., Turner, R.M. (Eds.), Repeat

558 Photography: Methods and Application in Natural Sciences. Island Press, Washington, D.C., pp.

559 145-166.

560

561 McClaran, M.P., Wei, H., 2014. Recent drought phase in a 73-year record at two spatial scales:

562 implications for livestock production on rangelands in the Southwestern United States.

563 Agricultural and Forest Meteorology. 197, 40-51.

564

565 Molinar, F., Holechek, J., Galt, D., Thomas, M., 2002. Soil depth effects on Chihuahuan Desert 566 vegetation. Western North American Naturalist. 62, 300-306.

567

568 Noy-Meir, I., 1973. Desert ecosystems: environment and producers. Annual Review of Ecology 569 and Systematics. 4, 23-51.

570

571 Oksanen, J., Blanchet, F.G., Kindt, R., Legendre, P., Minchin, P.R., O'Hara, R.B., Simpson, 572 G.L., Solymos, P., Stevens, M.H.H., Wagner, H., 2013. Vegan: community ecology package. R 573 package version 2.0-7.

574 
575 Olsson, A.D., Betancourt, J., McClaran, M.P., Marsh, S.E., 2012. Sonoran Desert Ecosystem

576

577

578 Potgieter, A.B., Apan, A., Dunn, P., Hammer, G., 2007. Estimating crop area using seasonal time 579 580 581 582 583 584 585 586 587 for British Forests. Forestry Commission, Edinburgh 588

transformation by a C4 grass without the grass/fire cycle. Diversity and Distributions. 18, 10-21. series of Enhanced Vegetation Index from MODIS satellite imagery. Australian Journal of Agricultural Research. 58, 316-325.

\section{Pringle, H.J.R., Watson, I.W., Tinley, K.L., 2006. Landscape improvement, or ongoing} degradation - reconciling apparent contradictions from the arid rangelands of Western Australia. Landscape Ecology. 21, 1267-1279.

Ray, D., 2001. Ecological Site Classification, Version 1.7. A PC-Based Decision Support System

Reynolds, A., Richards, G., de la Iglesia, B., Rayward-Smith, V., 1992. Clustering rules: a comparison of partitioning and hierarchical clustering algorithms. Journal of Mathematical Modelling and Algorithms. 5, 475-504.

Sankaran, M., Hanan, N.P., Scholes, R.J., Ratnam, J., Augustine, D.J., Cade, B.S., Gignoux, J., Higgins, S.I., Le Roux, X., Ludwig, F., Ardo, J., Banyikwa, F., Bronn, A., Bucini, G., Caylor, K.K., Coughenour, M.B., Diouf, A., Ekaya, W., Feral, C.J., February, E.C., Frost, P.G.H., Hiernaux, P., Hrabar, H., Metzger, K.L., Prins, H.H.T., Ringrose, S., Sea, W., Tews, J., Worden, J., Zambatis, N., 2005. Determinants of woody cover in African savannas. Nature 438, 846-849. 
600 Twidwell, D., Allred, B.W., Fuhlendorf, S.D., 2013. National-scale assessment of ecological 601 content in the world's largest land management framework. Ecosphere. 4, art94, 602 http://dx.doi.org/10.1890/ES13-00124.1.

603

604 [USDA-NRCS] US Department of Agriculture, Natural Resources Conservation Service, 2013.

605 Ecological Site Information System. Available at: http://esis.sc.egov.usda.gov/ESIS/About.aspx. 606

607 Van Auken, O.W., 2000. Shrub invasions of North American semiarid grasslands. Annual 608 Review of Ecology and Systematics. 31, 197-215.

609

610 Van Auken, O.W., 2009. Causes and consequences of woody plant encroachment into western 611 North American grasslands. Journal of Environmental Management. 90, 2931-2942.

612

613 van Gool, D., Moore, G., 1999. Land evaluation standards for land resource mapping -

614 Guidelines for assessing land qualities and determining land capability in south-west Western 615 Australia, 2nd edition. Resource Management Technical Report 181.

616

617 Walker, B.H., Langridge, J.L., 1997. Predicting savanna vegetation structure on the basis of plant 618 available moisture (PAM) and plant available nutrients (PAN): A case study from Australia. 619 Journal of Biogeography. 24, 813-825. 620 
621 Whisenant, S.G., 1990. Changing fire frequencies on Idaho’s Snake River Plains: ecological and

622 management implications. US Department of Agriculture, Forest Service, Intermountain

623 Research Station, General Report INT-276, Ogden, UT, pp. 4-10.

624

625 Wonkka, C.L., Twidwell, D., West, J.B., Rogers, W.E., 2016. Shrubland resilience varies across

626 soil types: implications for operationalizing resilience in ecological restoration. Ecological

627 Applications. 26, 128-145. doi:10.1890/15-0066

628

629 Wu, X.B., Archer, S.R., 2005. Scale-dependent influence of topography-based hydrologic

630 features on patterns of woody plant encroachment in savanna landscapes. Landscape Ecology.

$63120,733-742$. 


\section{Figure captions}

633

634 Fig. 1. Example illustrating how monitoring plots were clustered based on their temporal velvet 635 mesquite canopy cover profiles. Each line corresponds to time series data collected at a single 636 monitoring site. Monitoring sites were grouped by considering all measurements in a time series 637 as distinct (potentially correlated) attributes of a particular site. This approach is similar to how 638 multivariate statistics are used in plant ecology to group sample sites based on multiple plant 639 species or in remote sensing to group pixels based on multiple spectral bands. Only two of the 640 four derived clusters are shown here for clarity.

641 [Note to editors: This figure consists of a single image (WilliamsonEI2016_Fig1.TIF). It is 642 intended to fit a single column]

644 Fig. 2. Comparison of velvet mesquite and Lehmann lovegrass time series summary statistics 645 derived for each SRER monitoring plot. A, Mean velvet mesquite canopy cover and mean 646 Lehmann lovegrass basal cover measured over the study period. B, Maximum velvet mesquite 647 canopy cover and maximum Lehmann lovegrass basal cover measured over the study period. 648 Analysis periods were 1975-2012 for velvet mesquite canopy cover and 1984-2012 for

649 Lehmann lovegrass basal cover. Box plots indicate the $10^{\text {th }}, 25^{\text {th }}, 50^{\text {th }}, 75^{\text {th }}$, and $90^{\text {th }}$ percentiles 650 and outliers. LU indicates the loamy upland ecological site class; SLD, sandy loam deep; and 651 SLU, sandy loam upland.

652 [Note to editors: This figure consists of two images (WilliamsonEI2016_Fig2A.TIF and 653 WilliamsonEI2016_Fig2B.TIF). The images can be arranged vertically to fit a single column or 654 horizontally to fit two columns.] 
Fig. 3. A, Variation in velvet mesquite canopy cover trends among study plots and ecological

657 site classes. A multivariate clustering routine was used to group plots having similar velvet

658 mesquite canopy cover through time. Symbols indicate median velvet mesquite canopy cover of 659 each group at each sample date, and error bars indicate the $25 \%$ and $75 \%$ quantiles. B, The 660 number of plots from each group that is represented in each ecological site class. LU indicates 661 the loamy upland ecological site class; SLD, sandy loam deep; and SLU, sandy loam upland. 662 [Note to editors: This figure consists of a single image (WilliamsonEI2016_Fig3.TIF). It is 663 intended to fit 1.5 columns]

664

665 Fig. 4. A, Variation in Lehmann lovegrass basal cover trends among study plots and ecological 666 site classes. A multivariate clustering routine was used to group plots having similar Lehmann 667 lovegrass basal cover through time. Symbols indicate median Lehmann lovegrass basal cover of 668 each group at each sample date, and error bars indicate the $25 \%$ and $75 \%$ quantiles. B, The 669 number of plots from each group that is represented in each ecological site class. LU indicates 670 the loamy upland ecological site class; SLD, sandy loam deep; and SLU, sandy loam upland. 671 [Note to editors: This figure consists of a single image (WilliamsonEI2016_Fig4.TIF). It is 672 intended to fit 1.5 columns]

673

674 Fig. 5. A, Variation in Lehmann lovegrass density trends among study plots and ecological site 675 classes. A multivariate clustering routine was used to group plots having similar Lehmann 676 lovegrass density through time. Symbols indicate median Lehmann lovegrass density of each 677 group at each sample date, and error bars indicate the $25 \%$ and $75 \%$ quantiles. B, The number of 
678 plots from each group that is represented in each ecological site class. LU indicates the loamy

679 upland ecological site class; SLD, sandy loam deep; and SLU, sandy loam upland.

680 [Note to editors: This figure consists of a single image (WilliamsonEI2016_Fig5.TIF). It is

681 intended to fit 1.5 columns] 


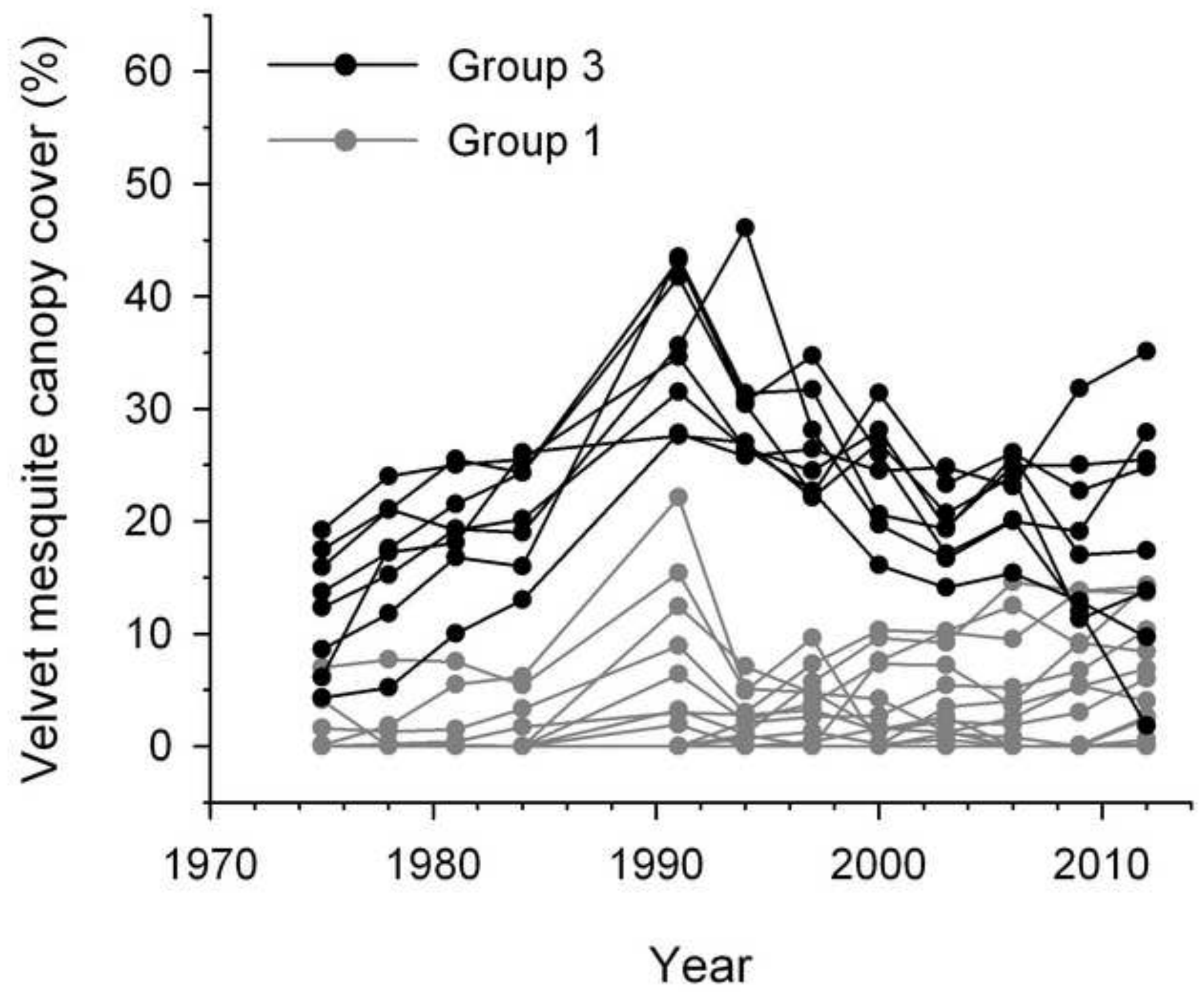




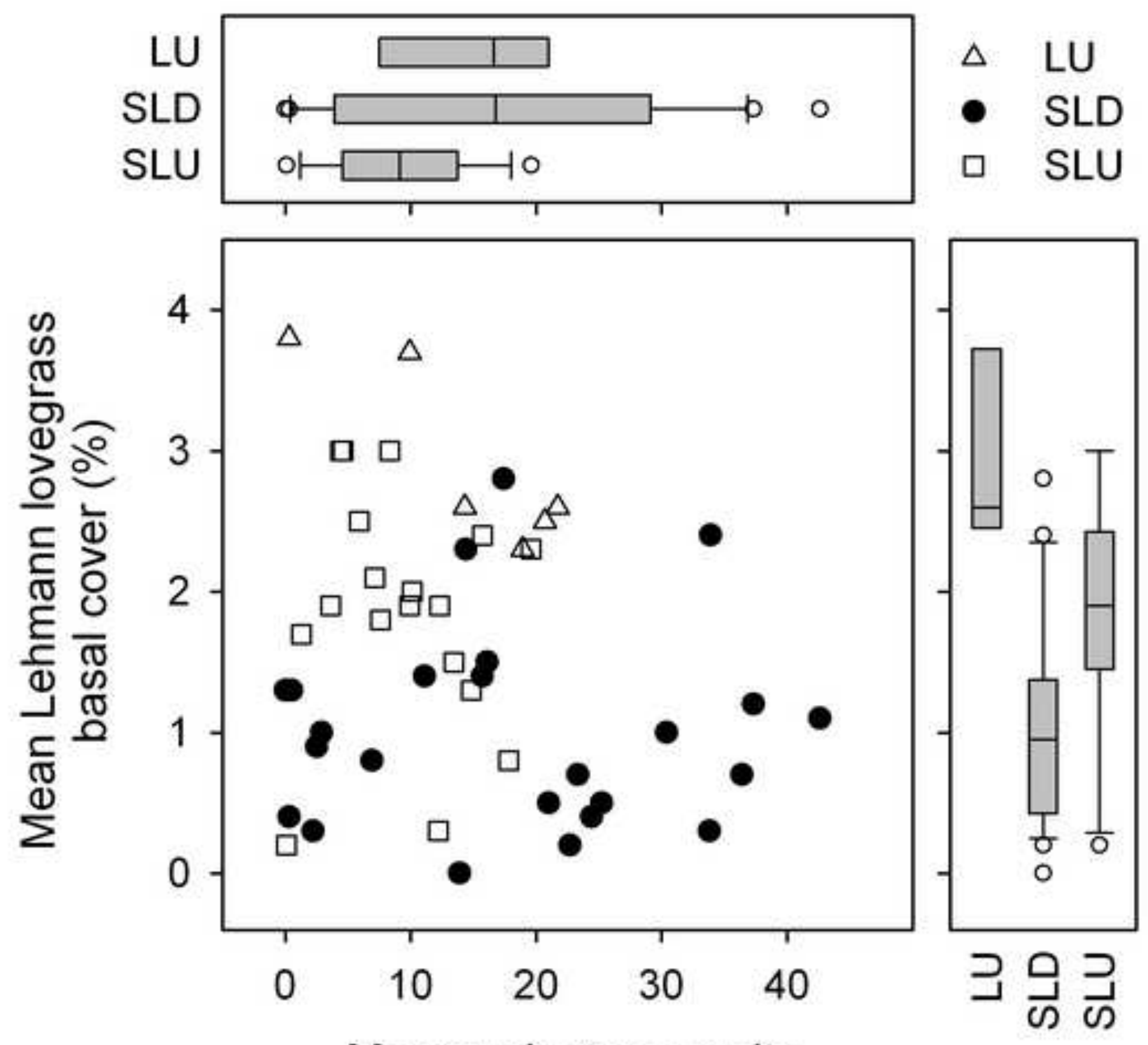

Mean velvet mesquite canopy cover (\%) 


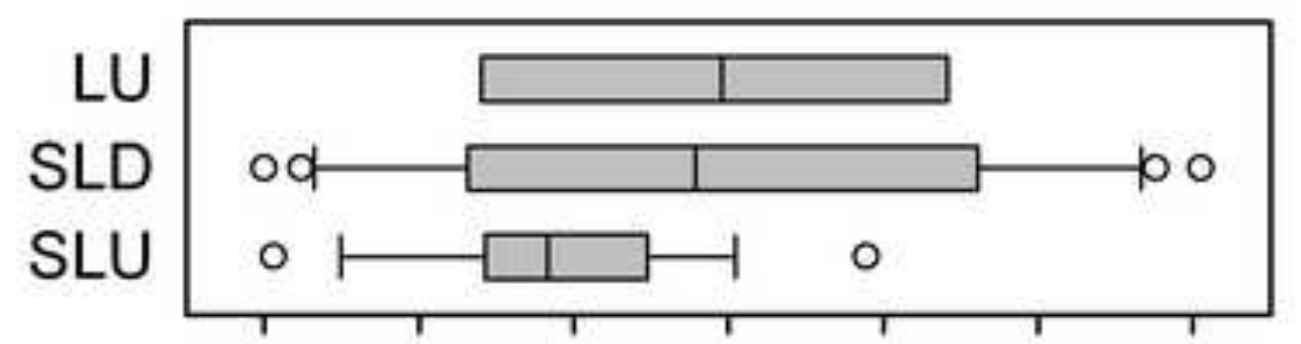

$\begin{array}{ll}\triangle & \text { LU } \\ - & \text { SLD } \\ \square & \text { SLU }\end{array}$

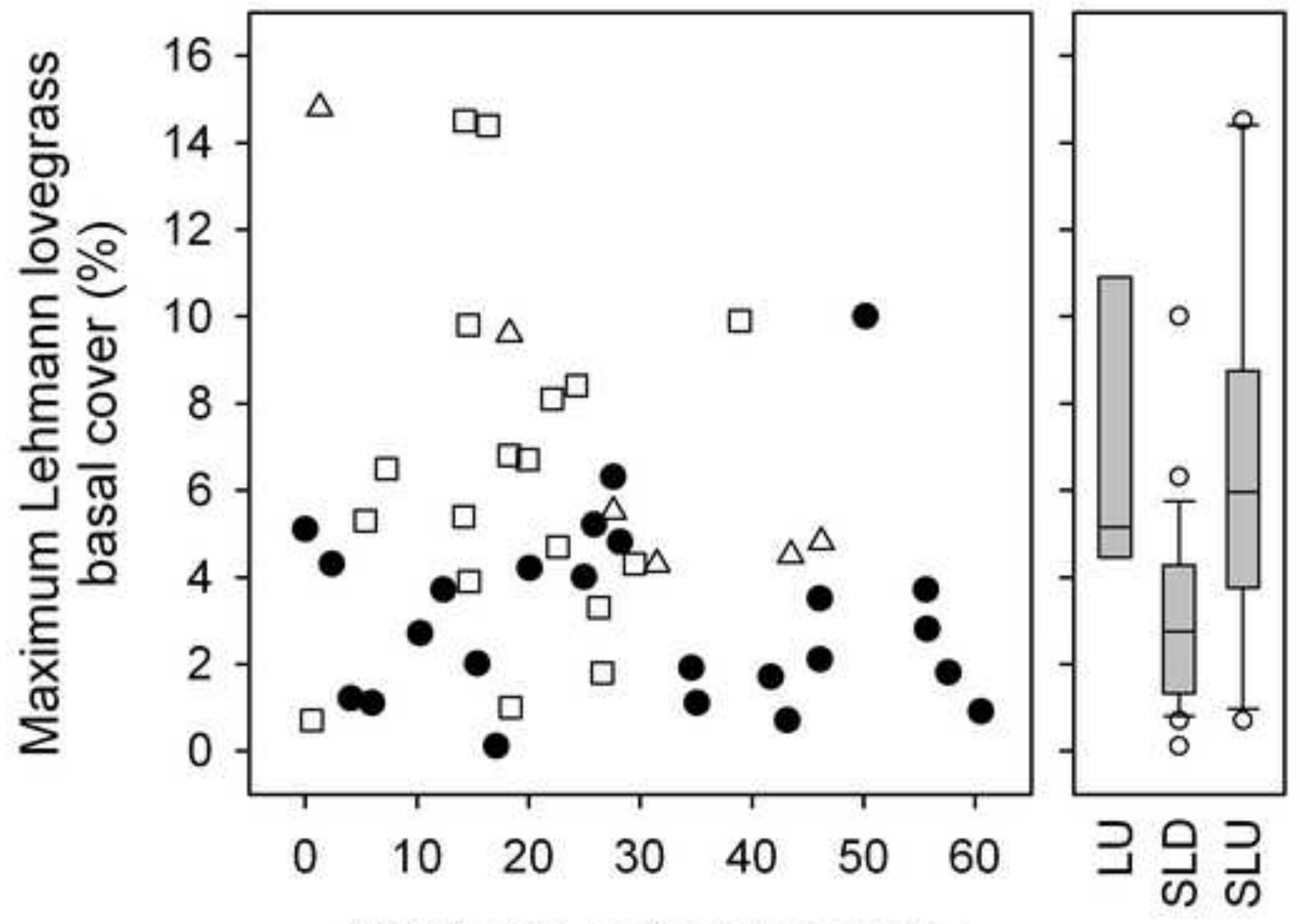

Maximum velvet mesquite canopy cover (\%) 

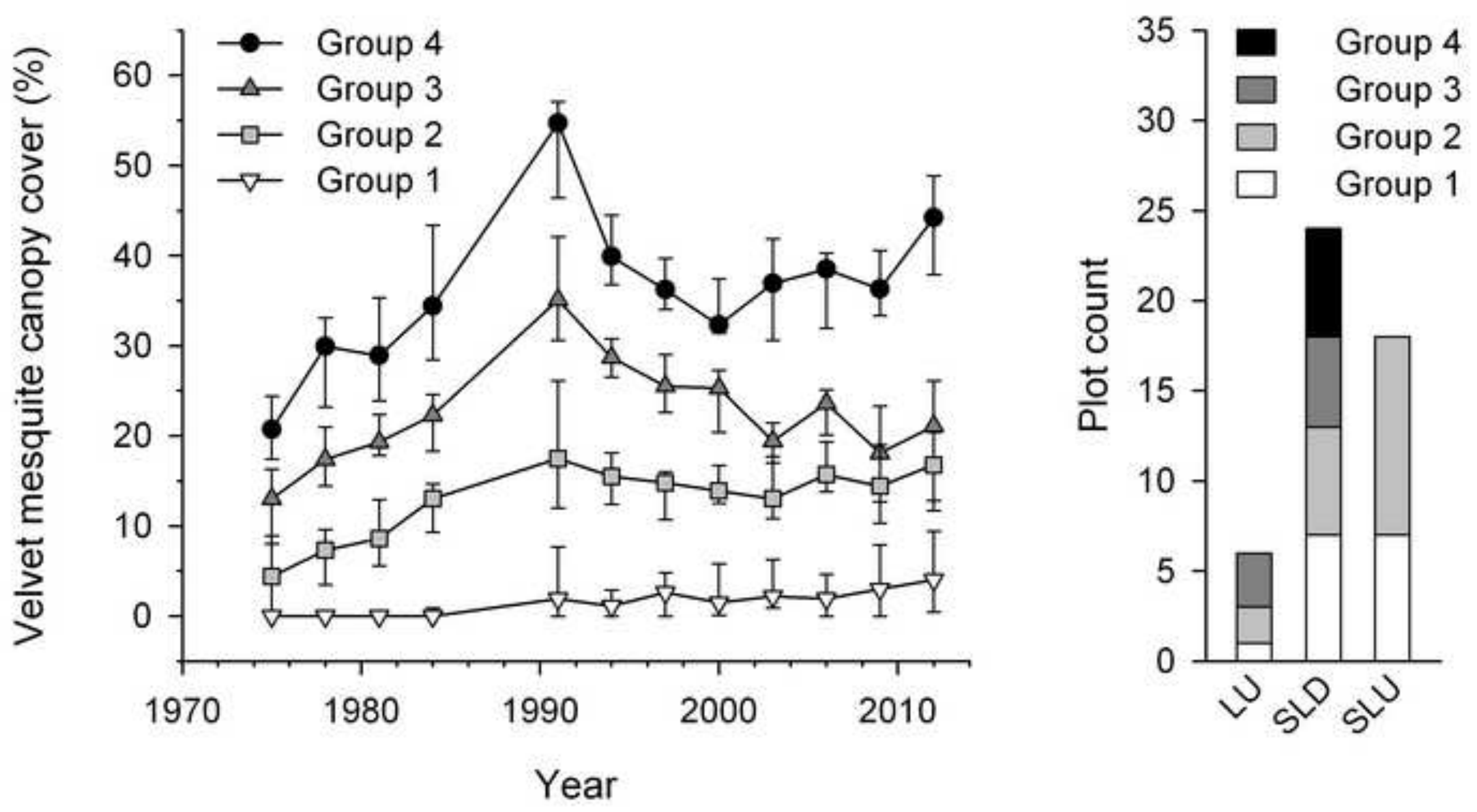

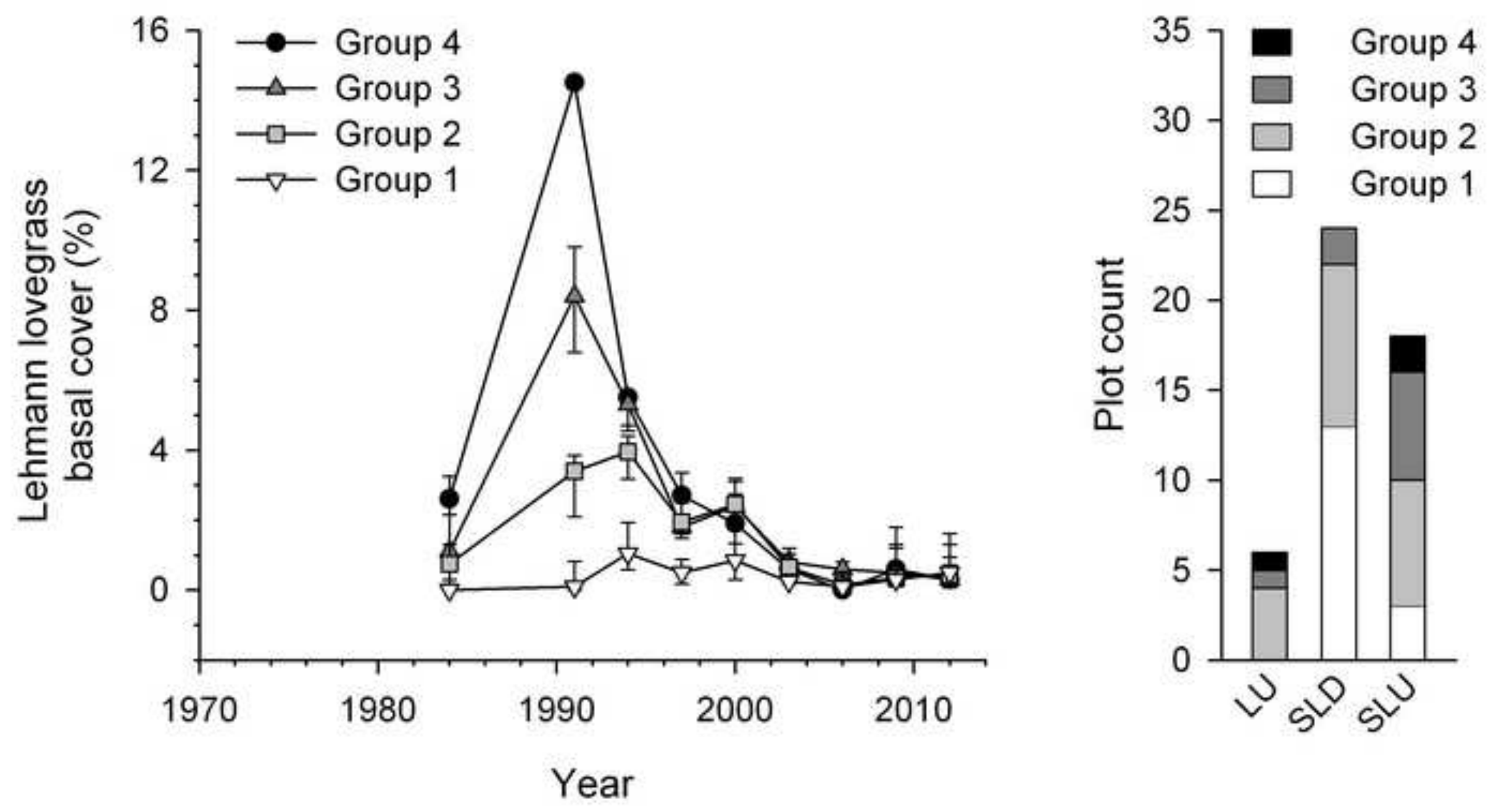

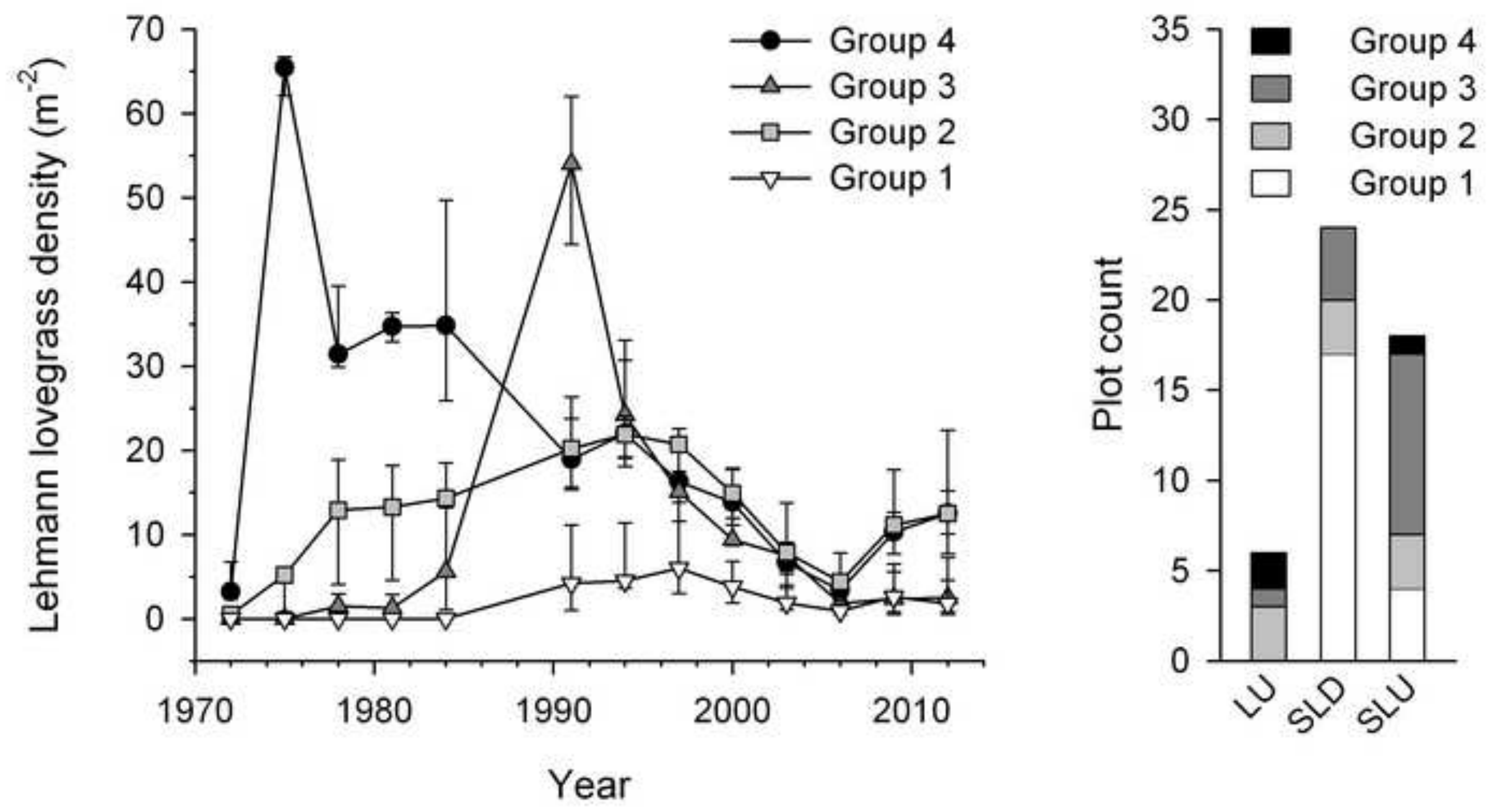